\title{
Development and Psychometric Properties of the Adversity and Stress Scale (ASS): Validation in the Adult Mexican Population
}

\author{
Miriam Arroyo-Belmonte ${ }^{1} \cdot$ Guillermina Natera-Rey ${ }^{2}$ (D ) Marcela Tiburcio-Sainz ${ }^{2}$. \\ Nora Martínez-Vélez ${ }^{2}$
}

Accepted: 27 September 2021

(c) The Author(s), under exclusive licence to Springer Science+Business Media, LLC, part of Springer Nature 2021

\begin{abstract}
Since stress is known to play a role in the development of physical and mental illness, empirically validated measurements are required to assess the effect of adverse events such as the COVID-19 pandemic. The purpose of this study was to develop and evaluate the psychometric properties of the Adversity and Stress Scale (ASS). A sample of 3937 adults living in Mexico was used. The structure of the instrument was evaluated using exploratory factor analysis (EFA) and confirmatory factor analysis (CFA). Construct validity was measured through associations between the ASS and psychological symptoms. In the EFA, the relational and contextual dimensions of stress were identified. A good fit was obtained in the CFA $(\mathrm{CFI}=0.980$, RMSEA =0.040). The ASS score was associated with all the selected variables in the expected direction, and internal consistency was $\alpha=.86$. The ASS is a valid, reliable measure, with the potential to be used in other adverse events.
\end{abstract}

Keywords Adverse events $\cdot$ Stress $\cdot$ COVID-19 $\cdot$ Scale $\cdot$ Validity $\cdot$ Reliability

Adverse events such as the COVID-19 pandemic have major consequences for physical and mental health (Burtscher et al., 2020; Chew et al., 2020; Ghebreyesus, 2020; Torales et al., 2020; Yan et al., 2021). The impact of these types of events can be explained by the stress they cause (Slavich, 2020). The effect of the latter on the immune system is well known (Morey et al., 2015; Park et al., 2019; Segerstrom, 2010) and directly influences the likelihood of infection (Burtscher et al., 2020).

Stress also plays a significant role in mental health and psychological well-being (Park et al., 2019; Wethington, 2016). Research has demonstrated that stress has been implicated in the development of anxiety and depressive disorders (Connolly et al., 2010; Park et al., 2019) and shaping behavioral responses (Taylor et al., 2020a). In

Guillermina Natera-Rey

naterar@imp.edu.mx; guillenatera@yahoo.com.mx

1 School of Medicine, National Autonomous University of Mexico, Mexico City, Mexico

2 Department of Social Sciences in Health, Direction of Epidemiological and Psychosocial Research, Instituto Nacional de Psiquiatría Ramón de la Fuente Muñiz, Calzada México-Xochimilco No. 101, Col. San Lorenzo Huipulco, 14370 Mexico City, CP, Mexico 
relation to epidemics, it has been documented that people with low anxiety before a viral outbreak engage less in hygiene behaviors or social distancing measures, while those with excessive anxiety are more likely to participate in socially disruptive behaviors (Asmundson \& Taylor, 2020).

This is particularly relevant given recent findings. For example, in China, over $25 \%$ of the general population experienced moderate to severe levels of stress- or anxietyrelated symptoms (Qiu et al., 2020). Likewise, it is important to recognize that the current pandemic is an adverse event with specific characteristics. As Biondi and Iannitelli (2020) point out, it is an unconventional event that is both individual and collective, causing persistent stress that can begin as acute and lead to chronic stress. It is characterized by efforts to adapt to the risk of infection, which also results in a psychosocial and economic effort to withstand the situation of self-isolation and emergency lockdowns, requiring damage management before and after the pandemic.

Evaluating this situation poses additional challenges to those already entailed by stress measurement (Harkness \& Monroe, 2016; Wethington, 2016). Most of the evidence in population studies on the role of stressors in human disease in population studies has been drawn from the study of stressful life events, usually measured by Life Events Scales (Cohen et al., 1995). These are lists of events and external situations (stressors) thought to create a level of demand that exceeds a person's ability to adapt (Wethington, 2016).

However, this type of measurement rarely identifies the impact of events on the context and people's relationships, or the dimensions of stress involved in the health-disease process, either immediately or in the long term (Cohen et al., 1995; Wethington, 2016). Findings from a systematic review revealed that only half the instruments designed to measure stressful events provide evidence of their association with health problems, while their psychometric properties are only reported in a few cases (Motrico et al., 2017).

In this context, it is essential to develop brief measurement tools and incorporate new measurement schemes that will shed light on the impact a stressor as unique as the current pandemic has on various areas of people's lives and its possible link with health outcomes. Although various means of measuring fear and anxiety related to the COVID-19 pandemic have recently emerged (Ahorsu et al., 2020; Lee, 2020; Mertens et al., 2020; Taylor et al., 2020b), it is important to have a functional measurement tool for population studies that considers their possible psychosocial impact, beyond the fear of infection or contagion.

Therefore, this study developed and validated a scale assessing the stress levels of the COVID-19 contingency (a single stressful event) but considering its impact on various aspects of people's lives (such as housing, work/school, couple relationships, family, health, personal finances, and socio-environmental conditions). This paper presents the development of the Adversity and Stress Scale (ASS) and determines its psychometric properties: the factor structure, reliability as internal consistency, and convergent and construct validity.

\section{Method}

The study was conducted in two phases: (i) design of the conceptual framework and construction of the Adversity and Stress Scale and (ii) evaluation of its reliability, internal consistency, convergent and construct validity. 


\section{Phase I. Design of Conceptual Framework and Construction of ASS Scale}

The Adversity and Stress Scale was constructed by examining the relevant literature (Motrico et al., 2017; Wethington, 2016) and consulting stress and mental health experts in Mexico.

It focuses on evaluating the stress levels caused by a single adverse event, the COVID-19 lockdown, and its repercussions on everyday life and interpersonal relationships, to understand its impact (Cohen et al., 1995). Given that this event has potentially long-term repercussions (Biondi \& Iannitelli, 2020), the ASS was constructed considering the type of chronic stress measurement undertaken by other instruments, such as the Long-Term Difficulties Inventory (Rosmalen et al., 2012), in the context of Life Events Scales in epidemiological studies and among the general population (Motrico et al., 2017).

Likewise, the construction of the ASS and its dimensions considered the model for classifying chronic stress into interpersonal and non-interpersonal stress (Connolly et al., 2010; Hammen, 1991, 2006). Interpersonal stress refers to the discord that may emerge in relations between people, in which a particular relationship may be conflictive, unreliable, or unreciprocated, or because of the lack of close, trusting relationships (Shih et al., 2006). Conversely, stressful factors that are not created by the dynamics of relationships are regarded as non-interpersonal or contextual stressful factors (Shih et al., 2006). These include financial problems, academic or work difficulties, neighborhood crime, and poor health (Rudolph et al., 2000; Sheets \& Craighead, 2014).

By measuring a single current adverse event, the scale also attempted to prevent the memory biases these scales usually display and offset the failure to include an adequate, representative sample of adverse events that occur in people's lives (Cohen et al., 1995; Harkness \& Monroe, 2016).

To assess the content validity of the initial version of the scale comprising 20 items (ten in the interpersonal stress dimension and ten in the contextual stress dimension), a group of six experts was asked to rate each item on a scale of one to five regarding the stressful effect of the adverse event (lockdown due to the pandemic) on various spheres of people's lives. The 12 items the reviewers scored highest for relevance and coverage were kept, and another item related to social isolation was incorporated at their suggestion. This review resulted in a 13-item scale, which was subsequently piloted with 30 participants with similar characteristics to those in the final sample, to evaluate the clarity and full understanding of the instructions, items, and response options. The participants easily understood what each of the items referred to.

\section{Phase II. Evaluation of Reliability, Internal Consistency, and Convergent and Discriminant Validity}

During this phase, the ASS was incorporated into a larger study on substance use in the Mexican population during lockdown (Tiburcio et al., 2020).

\section{Study Design}

It is a descriptive, exploratory, cross-sectional study conducted through an online survey. 


\section{Participants}

The survey was designed for people over 18 in Mexico, who agreed to take part voluntarily in the study. A total of 4127 subjects participated.

\section{Instruments}

For the study of convergent and construct validity, the Stress Generation Model of Depression (Hammen, 1991, 2006; Sewart et al., 2019; Slavich, 2020) was used as the nomological network, from which variables positively and negatively associated with stress were selected. Measurements related to depressive symptoms (Ozamiz-Etxebarria, Dosil -Santamaria, Picaza-Gorrochategui, and Idoiaga-Mondragon 2020; Park et al., 2015; Park et al., 2019), one's emotional state during the pandemic (Sandín et al., 2020), and perceived threat were included together with analog measures on stress and perception of the state of physical and mental health (Chew et al., 2020; Prins et al., 2008; Vindegaard \& Benros, 2020).

Demographic Data Questionnaire This included sex, age, educational attainment, marital status, residence in Mexico, and occupation variables.

Adversity and Stress Scale This scale comprises 13 items investigating the stress levels experienced since the start of the COVID-19 lockdown in various aspects of life, including housing, work/school, couple relationships, family, isolation status, health, personal finances, leisure, socio-environmental conditions, and stress in other areas, according to a Likert scale with the following response options: not at all stressful (0), slightly stressful (1), somewhat stressful (2), stressful (3), and very stressful (4). The total score on the scale can range from 0 to 52, with higher scores indicating greater stress.

Patient Health Questionnaire 2 (PHQ-2) This questionnaire comprises two questions making it possible to identify depressive symptoms in the previous 2 weeks. It has four response options ranging from $0=$ never to $3=$ almost every day, the maximum score that can be obtained being 6 (Kroenke et al., 2003). It has been validated and used in different contexts and languages, including Spanish, and shown good psychometric properties (Rodríguez-Muñoz et al., 2017). In Mexico, its discriminating power was evaluated with indigenous women, and it was found that the best cut-off point is 3 , with a sensitivity of $80.00 \%$ and a specificity of $86.8 \%$ (Arrieta et al., 2017).

Emotional State during the Pandemic This question consists of a list of 11 emotions that may be experienced during confinement, six related to positive emotions (joy, relaxation, tranquility, happiness, hope, and pleasure), and five to negative ones (fear, vulnerability, worry, despair, and anger), whose Likert scale response options range from $1=$ not at all to $5=\mathrm{a}$ lot.

Perceived Coronavirus Threat Questionnaire, Short Version (Conway III et al., 2020) This questionnaire includes questions regarding the perception of threat or concerns about the coronavirus, with seven Likert scale response options ranging from $1=$ does not apply to my case to $7=$ fully applicable in my case. Participants answered three items on 
how threatened or worried they were about COVID-19, such as "Thinking about the coronavirus (COVID-19) makes me feel threatened." It was translated into Spanish for the study and a reliability coefficient of 0.894 was obtained for this sample.

\section{Analog Measures of Stress and Perception of the Person's Physical and Mental Health}

Status Stress levels were evaluated through the question "During lockdown, how much have you experienced stress?" on a scale of 1 to 5 , with 5 representing the greatest stress. Regarding health status, the question "In general, how do you regard your health status?" was included, with response options ranging from 1 to 5 , with 1 representing poor health and 5 excellent health. As for the impact on mental health, the question "The coronavirus outbreak has negatively affected my psychological health" was taken from the Coronavirus Impacts Questionnaire (Conway III et al., 2020), evaluated on a scale of seven response options ranging from $1=$ not applicable in my case to $7=$ fully applicable in my case.

\section{Procedure}

Data were collected through a self-report questionnaire on the Google Forms platform, a free application for administering surveys, between May 1 and June 30, 2020. The research and data collection protocol were approved by the Ethics Committee of the Ramón de la Fuente Muñiz-INPRFM National Institute of Psychiatry (EP12020), and all respondents gave their consent prior to starting the survey. Participation was sought through online announcements on the INPRFM website, email campaigns, social networks, and messaging campaigns via WhatsApp.

\section{Data Analysis}

Statistical analyses were performed using IBM SPSS Statistics 25. For item discrimination, the means, standard deviations, skewness, and kurtosis were calculated, and $t$-scores were determined to compare the high group with the low group for each of the items. Reliability was obtained through internal consistency (Cronbach's $\alpha$ ), corrected item-total correlations, and alpha if the item was eliminated. To examine the factorial structure and factor loads and determine the percentage of variance explained by the factor, an exploratory factor analysis (EFA) was carried out using the maximum likelihood estimation (Schermelleh-Engel et al., 2003), after Kaiser-Meyer-Olkin's (KMO) sampling adequacy test and Bartlett's sphericity tests (Hair et al., 2014) had been performed. The factorial structure of the ASS was analyzed using confirmatory factor analysis (CFA) in IBM SPPS AMOS 24. The model tests were based on the maximum likelihood estimate. The following indices were used to evaluate the quality of the model (Browne \& Cudeck, 1992; Hu \& Bentler, 1999): the $\chi^{2}$ goodness of fit test and the $\chi^{2 /}$ $\mathrm{gl}(\mathrm{CMIN} / \mathrm{DF}$ ) ratio, the GFI (Goodness of Fit Index), AGFI (Adjusted Goodness of Fit Index), CFI (Comparative Fit Index), and NFI (Normed Fit Index), together with those to test errors such as RMR (Root Mean Square Residual) and RMSEA (Root Mean Square of Approximation). Correlational, variance, and $t$-test analyses were performed to evaluate convergent validity, according to the level of measurement of the variables. Carlson and Herdman (2012) recommend convergent validations above $r=.70$, while those below $r=.50$ should be avoided. 


\section{Results}

\section{Characterization of Sample}

A total of 4127 people answered the survey. The sample considered for this study comprised 3937 subjects, since cases in which non-committal responses were identified through item discrimination analysis were excluded. The sample was divided into two different subsamples randomly selected to undertake the exploratory and confirmatory factor analyses. The characteristics of the subsamples for conducting the EFA and CFA are given in Table 1 . In the total sample, the mean age was $37(\mathrm{SD}=12,586) ; 72.5 \%$ were women,

Table 1 Demographic data of sample $(N=3937)$

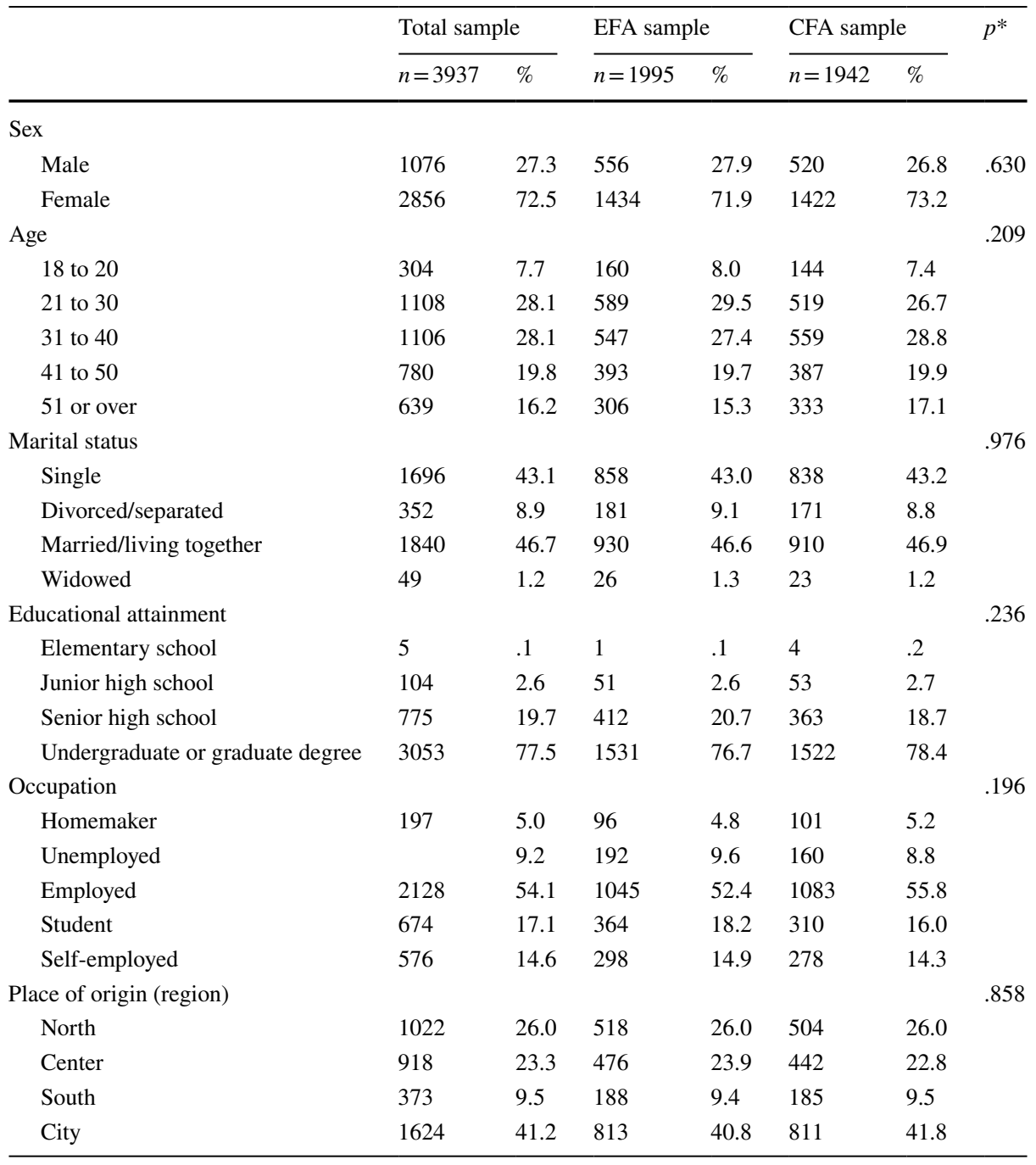

$* X^{2}$, Mann-Whitney $U$ test according to the level of measurement of variables 
and $41.2 \%$ of the subjects were from the capital, Mexico City. A total of $77.5 \%$ of the sample had completed undergraduate or graduate studies; $46.7 \%$ said they lived with their partners, $54 \%$ had a job, and $77 \%$ reported having a steady income.

\section{Item Analysis}

After a discrimination analysis of the ASS items had been conducted, one item was eliminated owing to the high frequency of response in a single category, due to bias and kurtosis, because it failed to distinguish between extreme groups and the item-total score correlation. In the remaining items, the average percentage of participants for each of the five response options was $23 \%$. Bias values ranged from -0.21 to 1.21 . The difference between the total scores of the low-stress group scale (mean $=.439$; SD. $=.202)$ and those of highstress group scale $($ mean $=2.57 ; \mathrm{SD}=.429)$ was significant $(p<.001)$ across all items. The item-total score correlations lay within a range of 0.59 to 0.89 .

\section{Exploratory Factor Analysis}

The EFA was conducted in a sample of 1995 people. The value of the Kaiser Meyer-Olkin (KMO) measure of sampling adequacy for the 12 items on the scale was .913. The significance of Bartlett's sphericity test was less than $p<0.001$. The analysis yielded two dimensions: contextual factors and relational factors, which together explained $50 \%$ of the total variance (Table 2).

\section{Confirmatory Factor Analysis}

In half the sample $(n=1942)$, the CFA was carried out for the model obtained in the EFA and for the one-dimensional scale for comparative purposes. A better fit was found with the two-dimensional model with 11 items, as the item "problems in the neighborhood" was eliminated. Figure 1 shows the standardized factorial coefficients, while Table 3 shows the fit indices of the model with 11 items. The correlation between factors was $r=.79$.

\section{Internal Consistency Index}

The internal consistency index for the total scale of 11 items was $\alpha=.86$, for the subscale of "Relational factors" $\alpha=.80$, and for the subscale of "Relational factors" $\alpha=78$. In none of the items was the "alpha if the element is eliminated" greater than that obtained for the full scale (Table 2).

\section{Convergent Validity}

To establish the convergent validity of the scale, it was correlated with the Perceived Coronavirus Threat Questionnaire (PCTQ) and the analog stress measurement, which measures similar constructs to the ASS. Table 4 shows the correlation analyses performed between the scores of the two subscales and the total scale and the scores of the applied instruments $(n=3937)$. The index of correlation with the Perceived Coronavirus Threat Questionnaire was $r=.51$ with the total ASS score; $r=.56$ with the contextual dimension, and $r=.37$ for the relational dimension. In the case of analog stress measurement, a correlation of $r=.646$ 
Table 2 Exploratory factor analysis of the scale, reliability indices, and descriptive measures

\begin{tabular}{|c|c|c|c|}
\hline \multicolumn{2}{|l|}{ Items } & \multicolumn{2}{|l|}{ Dimensions } \\
\hline & & $\begin{array}{l}\text { Contextual dimen- } \\
\text { sion }\end{array}$ & $\begin{array}{l}\text { Relational } \\
\text { dimension }\end{array}$ \\
\hline Situations related to space or housing & & .414 & .731 \\
\hline Work or school & & .492 & .633 \\
\hline Partner relationship & & .312 & .722 \\
\hline Relationship with relatives or friendship & & .450 & .711 \\
\hline Isolation or loneliness & & .545 & .580 \\
\hline Situations related to free time & & .575 & .661 \\
\hline Situations related to money & & .656 & .475 \\
\hline Their own health & & .732 & .407 \\
\hline The health of relatives or people close to them & & .781 & .410 \\
\hline Leaving home & & .799 & .418 \\
\hline Difficulties in neighborhood or place of residence & & .542 & .424 \\
\hline \multirow[t]{2}{*}{ Current social and economic situation } & & .731 & .215 \\
\hline & Total & & \\
\hline Explained variance & $50.1 \%$ & & \\
\hline Cronbach's Alpha (11 item scale) & $\alpha .=86$ & $\alpha .=80$ & $\alpha .=.78$ \\
\hline Mean of 11 item scale* & 1.48 & 1.71 & 1.28 \\
\hline Standard deviation of 11 item scale & .865 & .991 & .903 \\
\hline
\end{tabular}

Alpha, mean, and standard deviation calculated using the whole sample $n=3937$

*Theoretical mean $=2$; range: 0 to 4

was obtained with the total scale, of $r=.61$ in the relational dimension, and $r=.56$ in the contextual scale. All the indices are in the expected direction and within the range recommended by Carlson and Herdman (2012), except the relationship between the relational dimension of ASS and the PCTQ, which is below .50.

\section{Construct Validity}

To establish construct validity, the ASS was correlated with the PHQ-2, negative and positive emotions during lockdown, and analog measures of the physical health status and psychological impact associated with the coronavirus. According to the nomological network, this construct should be positively related to depressive symptomatology, negative emotions, and psychological impact and negatively related to positive emotions and better health. This hypothetical pattern was obtained (Table 4). The results showed that subjects with high stress scores also had high scores in depressive symptomatology, negative emotions, and effects on mental health due to the coronavirus. An inverse relationship was observed for positive emotions and better health. A higher correlation was observed between the relational dimension of stress and depressive symptomatology and positive emotions, as has been observed in other studies (Connolly et al., 2010; Sewart et al., 2019). The highest correlations were obtained with the negative emotions scale during the pandemic $(r=.68)$ and the lowest with the analog measure of health status $(-.28)$. Table 4 also displays the descriptive measures of the instruments. 


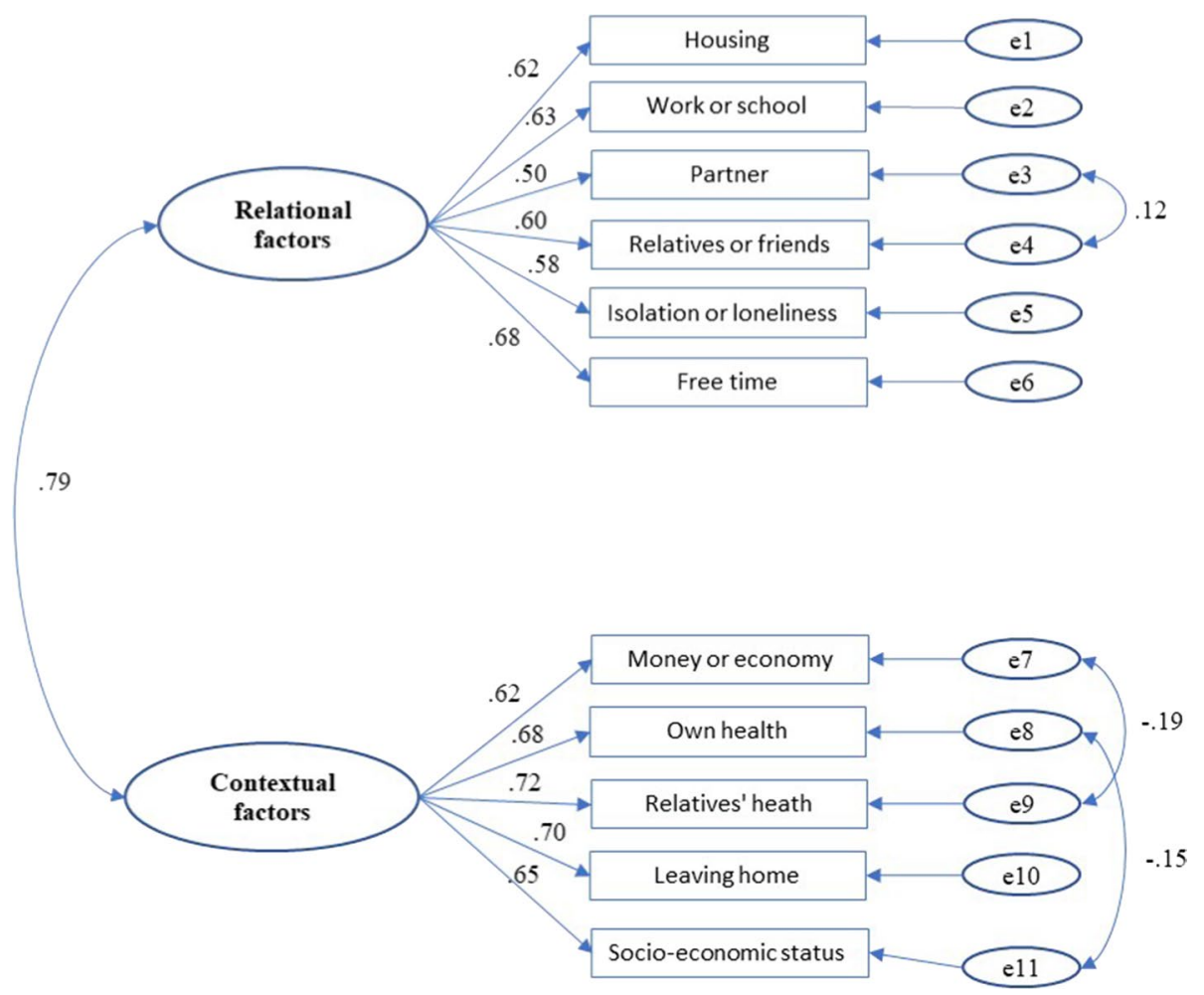

Fig. 1 CFA of the bifactor model of the ASS and fit indices

Table 3 Indices for the one- and two-dimensional models

\begin{tabular}{llllllll}
\hline Models & $\chi^{2} / \mathrm{gl} \mathrm{CMIN}$ & GFI & AGFI & CFI & NFI & SRMR & RMSEA (IC90\%) \\
\hline $\begin{array}{c}\text { One-dimen- } \\
\text { sional scale }\end{array}$ & $369.58 / 47=7.863$ & 0.968 & 0.946 & 0.953 & 0.94 & .057 & $.059(.054, .065)$ \\
$\begin{array}{c}\text { Two-dimen- } \\
\text { sional scale } \\
(11 \text { items })\end{array}$ & $167.94 / 40=4.127$ & 0.985 & 0.975 & 0.980 & 0.974 & .042 & $.040(.034, .047)$ \\
\hline
\end{tabular}

\section{ASS Scores in the Different Sample Groups}

Table 5 describes the means of the total scores of the ASS and its dimensions through the sociodemographic variables of sex, age, and occupation. In general, it is observed that women, people aged between 21 and 30, and unemployed persons obtained higher scores on the total scale and the contextual stressor. In both the total scale and its dimensions, statistically significant differences were identified between the sociodemographic categories presented. 
Table 4 Correlation indices of subscales and total ASS score with associated constructs

\begin{tabular}{|c|c|c|c|c|}
\hline & Mean (SD) & $\begin{array}{l}\text { Correlation with } \\
\text { total ASS ( } 11 \\
\text { items) }\end{array}$ & $\begin{array}{l}\text { Correlation with } \\
\text { relational dimen- } \\
\text { sion }\end{array}$ & $\begin{array}{l}\text { Correlation } \\
\text { with contextual } \\
\text { dimension }\end{array}$ \\
\hline Patient Health Questionnaire-2 & $2.27(1.77)$ & $.598 * *$ & $.604 * *$ & $.475^{* *}$ \\
\hline $\begin{array}{l}\text { Positive emotions during } \\
\text { lockdown }\end{array}$ & $2.84(.87)$ & $-.324 * *$ & $-.345^{* *}$ & $-.239 * *$ \\
\hline $\begin{array}{l}\text { Negative emotions during } \\
\text { lockdown }\end{array}$ & $3.13(1.05)$ & $.684 * *$ & $.606 * *$ & $.635^{* *}$ \\
\hline $\begin{array}{l}\text { Perceived threat from COVID- } \\
19\end{array}$ & $3.27(1.82)$ & $.513 * *$ & $.376^{* *}$ & $.560 * *$ \\
\hline $\begin{array}{l}\text { Analog measure of stress during } \\
\text { Lockdown }\end{array}$ & $3.49(1.26)$ & $.646^{* *}$ & $.610 * *$ & $.560 * *$ \\
\hline Analog measure of health status & $3.82(.82)$ & $-.280 * *$ & $-.223 * *$ & $-.287 * *$ \\
\hline $\begin{array}{l}\text { Analog measure of effects on } \\
\text { psychological health due to } \\
\text { coronavirus }\end{array}$ & $2.90(1.87)$ & $.590 * *$ & $.552 * *$ & $.517 * *$ \\
\hline
\end{tabular}

$* * p<.001$

Table 5 Total ASS score and its dimensions by sociodemographic variable

\begin{tabular}{|c|c|c|c|c|c|c|c|c|c|}
\hline & \multicolumn{3}{|c|}{ Total ASS } & \multicolumn{3}{|c|}{ Relational dimension } & \multicolumn{3}{|c|}{ Contextual dimension } \\
\hline & $\mathrm{N}$ & Mean & SD & $\mathrm{N}$ & Mean & $\mathrm{SD}$ & $\mathrm{N}$ & Mean & SD \\
\hline Sex & $* *$ & & & $* *$ & & & $* *$ & & \\
\hline Male & 1076 & 1.32 & 0.84 & 1076 & 1.14 & 0.88 & 1076 & 1.53 & 0.98 \\
\hline Female & 2856 & 1.54 & 0.87 & 2856 & 1.34 & 0.91 & 2856 & 1.78 & 1.02 \\
\hline Age & $* *$ & & & $* *$ & & & $* *$ & & \\
\hline $18-20$ & 304 & 1.55 & 0.84 & 304 & 1.57 & 0.90 & 304 & 1.53 & 1.01 \\
\hline $21-30$ & 1108 & 1.78 & 0.87 & 1108 & 1.61 & 0.91 & 1108 & 1.99 & 1.02 \\
\hline $31-40$ & 1106 & 1.51 & 0.84 & 1106 & 1.31 & 0.86 & 1106 & 1.75 & 1.01 \\
\hline $41-50$ & 780 & 1.32 & 0.81 & 780 & 1.08 & 0.82 & 780 & 1.60 & 0.99 \\
\hline 51 or over & 639 & 1.06 & 0.76 & 639 & 0.77 & 0.74 & 639 & 1.41 & 0.93 \\
\hline Occupation & $* *$ & & & $* *$ & & & $* *$ & & \\
\hline Homemaker & 197 & 1.46 & 0.89 & 197 & 1.17 & 0.87 & 197 & 1.81 & 1.10 \\
\hline Unemployed & 362 & 1.78 & 0.91 & 362 & 1.50 & 0.97 & 362 & 2.11 & 1.00 \\
\hline Employed & 2128 & 1.36 & 0.83 & 2128 & 1.17 & 0.85 & 2128 & 1.59 & 0.98 \\
\hline Student & 674 & 1.73 & 0.87 & 674 & 1.68 & 0.90 & 674 & 1.79 & 1.05 \\
\hline Self-employed & 576 & 1.45 & 0.86 & 576 & 1.14 & 0.89 & 576 & 1.81 & 1.00 \\
\hline
\end{tabular}

$t$-test and ANOVA by level of measurement of variables, ${ }^{*} p p<.001$

\section{Discussion}

This study describes the development of the Adversity and Stress Scale (ASS), as well as its validation in a sample of Mexican adults. The results show that the ASS has a twofactor structure with robust psychometric properties: relational, associated with the impact of interpersonal interactions as a source of stress, for example, situations related to work/ 
school or leisure management, and contextual, associated with changes in the context or situations in which there is a lower degree of control or interference by people, as in the case of the current social and economic situation.

Recent conceptualizations and measurements related to pandemic-associated distress have focused primarily on fear of contagion and tend to be one-dimensional (Ahorsu et al., 2020; Lee, 2020; Mertens et al., 2020). Conversely, research based on COVID stress scales, as in this case and another study (Taylor et al., 2020b), provides a broader, more nuanced conceptualization. The results of this study can be interpreted as confirmation we are facing a multicomponent construction, characterized by a network of symptoms interconnected with socioeconomic and context concerns, and another one with an impact on interpersonal relationships. This characterization coincides with the classification proposed by researchers into chronic stress (Connolly et al., 2010; Hammen, 1991, 2006), which has made it possible to improve the psychometric characteristics of the evaluation instruments and to study the phenomenon of stress and its repercussions on mental and physical health in greater detail (Sewart et al., 2019; Slavich, 2020).

Likewise, a clear association was found between depressive symptoms, negative emotions, perceived threat of COVID-19, and increased stress, as well as an inverse relationship with positive emotions and perception of good health. In addition to finding the expected associations, also reported in other studies (Burtscher et al., 2020; Chew et al. and Sim 2020), including research on scale validation (Sandín \& Chorot, 2017; Taylor et al., 2020 b), evaluation of this type of relationship meets the need for evidence on the association between stress instruments and health measures (Motrico et al., 2017).

These results provide evidence of convergent and construct validity and are in keeping with the Stress Generation Model of Depression, which has revealed the differential effect of stressful events, showing that people with depression or at a high risk of suffering from it usually report more stressful events (both interpersonal and non-interpersonal) than those who do not have this mental health problem. Interpersonal events have the greatest impact (Connolly et al., 2010; Hammen, 1991, 2006), while positive emotions play an important role, since they significantly reduce the effects of interpersonal stress on the severity of depressive symptomatology (Sewart et al., 2019).

Likewise, this scale has made it possible to identify population groups with the highest levels of stress due to COVID. These findings are consistent with what has been observed in other studies, as in the case of women (Rodríguez-Rey et al., 2020; Taylor et al., 2020a; Toledo-Fernández et al., 2020; Yan et al., 2021), young people (Barraza, 2020; OzamizEtxebarria et al., 2020; Rodríguez-Rey et al., 2020; Yan et al., 2021), and unemployed persons (Taylor et al., 2020a; Yan et al., 2021). These results have major theoretical and practical applications. On the one hand, the ASS can serve as a tool for understanding the stress associated with the COVID-19 pandemic and as a possible means of identifying the areas of life most affected. It can provide new information for the structure of more complex explanatory psychosocial models and contribute to what some authors have called the "COVID stress syndrome" (Taylor et al., 2020a), which could have an important preventive impact.

At the same time, the findings have practical implications for mental health planning. Studies have shown that during the acute phase of the pandemic, the impact on emotional health may be related to concerns about contracting the virus, lifestyle changes, and depressive and anxiety symptoms (Qiu et al., 2020; Rodríguez -Rey et al., 2020). After the acute phase, the economic recession, life changes, and continuous uncertainties about the future may continue to produce high stress levels (Biondi \& Iannitelli, 2020; Ghebreyesus, 2020), as has been the case in other pandemics 
(Hawryluck et al., 2004). Likewise, the scale can be useful as a predictive and follow-up measure in the adaptation to "normality" after the pandemic and for identifying people at risk of adverse emotional reactions both during and after the pandemic, although this point warrants further research.

Within the field of stress research, this study proposes a novel measurement alternative since the ASS evaluates a single adverse event while considering its impact on the broader context of people's lives. It emphasizes the identification of a range of possible psychosocial effects of a single event, which is especially relevant since the COVID19 pandemic is an unconventional stressor, with the potential to create chronic stress (Biondi \& Iannitelli, 2020). Evaluating a single adverse event prevents certain problems of evaluation through lists of events, such as the lack of reporting of its psychometric properties and the constraints imposed by the number of items included in the checklist (Wethington, 2016), while retaining the advantages of easy administration and marking (Harkness \& Monroe, 2016).

Likewise, the ASS has the potential to be used with other adverse events or crisis situations. It was designed so that it could easily be adapted to other pandemics or other adverse situations that affect various areas of life or have the potential to do so. Accordingly, it is a scale that could be useful for assessing stress in health and population research settings.

The present study has several limitations. First, convenience sampling reduces the generalizability of the findings. Second, the nature of the self-report cannot rule out the possibility that respondents will give answers affected by other factors. Third, subjects were not asked about the presence of a psychiatric diagnosis, which would have been useful for assessing the validity of the criteria. Fourth, at the time of the study, we were unable to find any other instrument measuring the same attributes proposed in the ASS. However, some scales have recently emerged (e.g., Taylor et al., 2020b), which could serve as references to improve the measurement of the convergent validity indices of our scale. Despite these limitations, the findings suggest that the ASS is an adequate, brief instrument for assessing COVID-19-related stress.

\section{Conclusions}

This study demonstrated that the Adversity and Stress Scale is a two-dimensional, elevenitem scale with robust psychometric properties, suggesting that it is an instrument with adequate characteristics to assess COVID-19-related stress, with the potential to be adapted and used for other adverse events or stressors with a broad impact.

Acknowledgements Miriam Arroyo-Belmonte was awarded a grant by the National Council of Science and Technology (CONACyT, 175986). The authors wish to thank Jazmin Sánchez and Morise Fernández for their support with the data collection and the Ramón de la Fuente Muñiz National Institute of Psychiatry, for its support in conducting the study.

\section{Declarations}

Ethics Approval All procedures adhered to the ethical standards of the National Institute of Psychiatry Ethics Board and with the Helsinki Declaration of 1975, as revised in 2000. Informed consent was obtained from all the subjects to be included in the study.

Conflict of Interest The authors declare no competing interests. 


\section{References}

Ahorsu, DK, Lin, CY, Imani, V., Saffari, M., Griffiths, MD, Pakpour, A. H. (2020). The fear of COVID19 scale: Development and initial validation. International Journal of Mental Health and Addiction. https://doi.org/10.1007/s11469-020-00270-8

Arrieta, J., Aguerrebere, M., Raviola, G., Flores, H., Elliott, P., Espinosa, A., \& Franke, M. F. (2017). Validity and utility of the patient health questionnaire (PHQ)-2 and PHQ-9 for screening and diagnosis of depression in rural Chiapas, Mexico: A cross-sectional study. Journal of Clinical Psychology, 73(9), 1076-1090. https://doi.org/10.1002/jclp.22390

Asmundson, G. J. G., \& Taylor, S. (2020). How health anxiety influences responses to viral outbreaks like COVID-19: What all decision-makers, health authorities, and health care professionals need to know. Journal of Anxiety Disorders, 71(March), 102211. https://doi.org/10.1016/j.janxdis.2020.102211

Barraza, A. (2020). El estrés informativo en tiempo de pandemia (COVID 19). Un estudio exploratorio en población mexicana. Praxis Investigativa ReDIE: Revista electrónica de la Red Durango de Investigadores Educativos, 12(23), 63-78.

Biondi, M., \& Iannitelli, A. (2020). CoViD-19 and stress in the pandemic: "sanity is not statistical." Rivista Di Psichiatria, 55(3), 1e-6e. https://doi.org/10.1708/3382.33568

Browne, M. W., \& Cudeck, R. (1992). Alternative ways of assessing model fit. Sociological Methods and Research, 21, 230-258.

Burtscher, J., Burtscher, M., \& Millet, G. P. (2020). (Indoor) isolation, stress and physical inactivity: Vicious circles accelerated by Covid-19? Scandinavian Journal of Medicine \& Science in Sports, 2. https://doi. org/10.1111/sms.13706

Chew, Q. H., Wei, K. C., Vasoo, S., Chua, H. C., \& Sim, K. (2020). Narrative synthesis of psychological and coping responses towards emerging infectious disease outbreaks in the general population: Practical considerations for the COVID-19 pandemic. Singapore Medical Journal, 61(7), 350-356. https:// doi.org/10.11622/smedj.2020046

Cohen, S., Kessler, R. C., \& Gordon, L. U. (1995). Strategies for measuring stress in studies of psychiatric and physical disorders. In S. Cohen, R. C. Kessler, \& U. G. Lynn (Eds.), Measuring stress: A guide for health and social scientists (pp. 3-26). Oxford University Press.

Connolly, N. P., Eberhart, N. K., Hammen, C. L., \& Brennan, P. A. (2010). Specifi city of stress generation: A comparison of adolescents with depressive, anxiety, and comorbid diagnoses. International Journal of Cognitive Therapy, 3, 368-379. https://doi.org/10.1521/ijct.2010.3.4.368

Conway, L. G., III, Woodard, S. R., \& Zubrod, A. (2020). Social psychological measurements of COVID19: Coronavirus perceived threat, government response, impacts, and experiences questionnaires. https://doi.org/10.31234/osf.io/z2x9a

Ghebreyesus, T. (2020). Addressing mental health needs: An integral part of COVID-19 response. World Psychiatry, 19(2), 129-130. https://doi.org/10.1002/wps.20768

Hammen, C. (1991). Generation of stress in the course of unipolar depression. Journal of Abnormal Psychology, 100, 555-561. https://doi.org/10.1037/0021-843X.100.4.555

Hammen, C. (2006). Stress generation in depression: Reflections on origins, research, and future directions. Journal of Clinical Psychology, 62, 1065-1082. https://doi.org/10.1002/jclp.20293

Hair, J. F., Black, W. C., Babin, B. J., \& Anderson, R. E. (2014). Multivariate data analysis (7th ed.). Pearson Education.

Harkness, K. L., \& Monroe, S. M. (2016). The assessment and measurement of adult life stress: Basic premises, operational principles, and design requirements. Journal of Abnormal Psychology, 125(5), 727745. https://doi.org/10.1037/abn0000178

Hawryluck, L., Gold, W. L., Robinson, S., Pogorski, S., Galea, S., \& Styra, R. (2004). SARS control and psychological effects of quarantine, Toronto, Canada. Emerging Infectious Diseases, 10(7), 12061212. https://doi.org/10.3201/eid1007.030703

Hu, L. T., \& Bentler, P. M. (1999). Cutoff criteria for fit indexes in covariance structure analysis: Conventional criteria versus new alternatives. Structural Equation Modeling, 6(1), 1-55. https://doi.org/10. 1080/10705519909540118

Kroenke, K., Spitzer, R. L., \& Williams, J. B. W. (2003). The patient health questionnaire-2: Validity of a two-item depression screener. Medical Care, 41(11), 1284-1292. https://doi.org/10.1097/01.MLR. $0000093487.78664 .3 \mathrm{C}$

Lee, S. A. (2020). Coronavirus anxiety scale: A brief mental health screener for COVID-19 related anxiety. Death Studies, 44(7), 393-391. https://doi.org/10.1080/07481187.2020.1748481

Mertens, G., Gerritsen, L., Duijndam, S., Salemink, E., \& Engelhard, I. M. (2020). Fear of the coronavirus (COVID-19): Predictors in an online study conducted in march 2020. Journal of Anxiety Disorders, 74(March). https://doi.org/10.1016/j.janxdis.2020.102258 
Morey, J. N., Boggero, I. A., Scott, A. B., \& Segerstrom, S. C. (2015). Current directions in stress and human immune function. Current Opinion in Psychology, 5, 13-17. https://doi.org/10.1016/j. copsyc.2015.03.007

Motrico, E., Rodero-Cosano, M. L., Álvarez-Gálvez, J., Salinas-Pérez, J. A., \& Moreno-Peral, P. (2017). Measures for the assessment of stressful life events in the Spanish adult population: A systematic review. Anales de Psicologia, 33(3), 556-567. https://doi.org/10.6018/analesps.33.3.236631

Ozamiz-Etxebarria, N., Dosil-Santamaria, M., Picaza-Gorrochategui, M., \& Idoiaga-Mondragon, N. (2020). Niveles de estrés, ansiedad y depresión en la primera fase del brote del COVID-19 en una muestra recogida en el norte de España. Cadernos de Saúde Pública, 36(4), e00054020. https://doi. org/10.1590/0102-311X00054020

Park, S., Hatim, A., Si, T. M., Jeon, H. J., Srisurapanont, M., Bautista, D., et al. (2015). Stressful life events preceding the onset of depression in Asian patients with major depressive disorder. International Journal of Social Psychiatry, 61(8), 735-742. https://doi.org/10.1177/0020764015577842

Park, C., Rosenblat, J. D., Brietzke, E., Pan, Z., Lee, Y., Cao, B., et al. (2019). Stress, epigenetics and depression: A systematic review. Neuroscience and Biobehavioral Reviews, 102(December 2018), 139-152. https://doi.org/10.1016/j.neubiorev.2019.04.010

Prins, M. A., Verhaak, P. F. M., Bensing, J. M., \& van der Meer, K. (2008). Health beliefs and perceived need for mental health of anxiety and depression-the patients' perspective explored. Clinical Psychology Review, 28(6), 1038-1058. https://doi.org/10.1016/j.cpr.2008.02.009

Qiu, J., Shen, B., Zhao, M., Wang, Z., Xie, B., \& Xu, Y. (2020). A nationwide survey of psychological distress among Chinese people in the COVID-19 epidemic: Implications and policy recommendations. General Psychiatry, 33(2), 19-21. https://doi.org/10.1136/gpsych-2020-100213

Rodríguez-Muñoz, M. F., Castelao-Legazpi, P. C., Olivares-Crespo, M. E., Soto-Balbuena, C., Izquierdo-Méndez, N., Ferrer-Barrientos, F. J., \& Huynh-Nhu, L. (2017). PHQ-2 como primer instrumento de cribado de la depresión prenatal. Revista Española de Salud Pública, 91, 1-8.

Rodríguez-Rey, R., Garrido-Hernansaiz, H., \& Collado, S. (2020). Psychological impact and associated factors during the initial stage of the coronavirus (COVID-19) pandemic among the general population in Spain. Frontiers in Psychology, 11(June). https://doi.org/10.3389/fpsyg.2020.01540

Rosmalen, J. G. M., Bos, E. H., \& De Jonge, P. (2012). Validation of the long-term difficulties inventory (LDI) and the list of threatening experiences (LTE) as measures of stress in epidemiological population-based cohort studies. Psychological Medicine, 42(12), 2599-2608. https://doi.org/10. 1017/S0033291712000608

Rudolph, K. D., Hammen, C., Burge, D., Lindberg, N., Herzberg, D., \& Daley, S. E. (2000). Toward an interpersonal life-stress model of depression: The developmental context of stress generation. Development and Psychopathology, 12(2), 215-234.

Sandín, B., \& Chorot, P. (2017). Cuestionario de Sucesos Vitales (CSV): Estructura factorial, propiedades psicométricas y datos normativos. Revista de Psicopatologia y Psicologia Clinica, 22(2), 95-115. https://doi.org/10.5944/rppc.vol.22.num.2.2017.19729

Sandín, B., Valiente, R. M., García-Escalera, J., \& Chorot, P. (2020). Impacto psicológico de la pandemia de COVID-19: Efectos negativos y positivos en población española asociados al periodo de confinamiento nacional. Journal of Psychopathology and Clinical Psychology, 1, 1-22. https://doi. org/10.5944/rppc.27569

Schermelleh-Engel, K., Moosbrugger, H., \& Müller, H. (2003). Evaluating the fit of structural equation models: Tests of significance and descriptive goodness-of-fit measures. Methods of Psychological Research Online, 8, 23-74.

Segerstrom, S. C. (2010). Resources, stress, and immunity: An ecological perspective on human psychoneuroimmunology. Annals of Behavioral Medicine, 40(1), 114-125. https://doi.org/10.1007/ s12160-010-9195-3

Sewart, A. R., Zbozinek, T. D., Hammen, C., Zinbarg, R. E., Mineka, S., \& Craske, M. G. (2019). Positive affect as a buffer between chronic stress and symptom severity of emotional disorders. Clinical Psychological Science, 7(5), 914-927. https://doi.org/10.1177/2167702619834576

Sheets, E. S., \& Craighead, W. E. (2014). Comparing chronic interpersonal and noninterpersonal stress domains as predictors of depression recurrence in emerging adults. Behaviour Research and Therapy, 63, 36-42. https://doi.org/10.1016/j.brat.2014.09.001

Shih, J. H., Eberhart, N. K., Hammen, C. L., \& Brennan, P. A. (2006). Differential exposure and reactivity to interpersonal stress predict sex differences in adolescent depression. Journal of Clinical Child \& Adolescent Psychology, 35, 103-115. https://doi.org/10.1207/s1537/s15374424jccp3501_9

Slavich, G. M. (2020). Social safety theory: A biologically based evolutionary perspective on life stress, health, and behavior. Annual Review of Clinical Psychology, 16, 265-295. 
Taylor, S., Landry, C. A., Paluszek, M. M., Fergus, T. A., McKay, D., \& Asmundson, G. J. G. (2020a). COVID stress syndrome: Concept, structure, and correlates. Depression and Anxiety, 37(8), 706-714. https://doi.org/10.1002/da.23071

Taylor, S., Landry, C. A., Paluszek, M. M., Fergus, T. A., McKay, D., \& Asmundson, G. J. G. (2020b). Development and initial validation of the COVID stress scales. Journal of Anxiety Disorders, 72(April), 1315. https://doi.org/10.1016/j.janxdis.2020.102232

Tiburcio, M., Martínez, N. A., Fernández, M., Sánchez, Y., Arroyo, M., \& Natera, G. (2020). Protocolo: Consumo de alcohol, tabaco y otras sustancias durante la pandemia de COVID-19. Instituto Nacional de Psiquiatría Ramón de la Fuente Muñiz.

Toledo-Fernández, A., Betancourt-Ocampo, D., Romo-Parra, H., Reyes-Zamorano, E., \& GongálezGonzález, A. (2020). A cross-sectional survey of psychological distress in a Mexican sample during the second phase of the COVID-19 pandemic. https://doi.org/10.31219/osf.io/wzqkh

Torales, J., O’Higgins, M., Castaldelli-Maia, J. M., \& Ventriglio, A. (2020). The outbreak of COVID-19 coronavirus and its impact on global mental health. International Journal of Social Psychiatry, 66(4), 317-320. https://doi.org/10.1177/0020764020915212

Vindegaard, N., \& Benros, M. E. (2020). COVID-19 pandemic and mental health consequences: Systematic review of the current evidence. Brain, Behavior, and Immunity., 89, 531-542. https://doi.org/10.1016/j. bbi.2020.05.048

Wethington, E. (2016). Life events scale. In G. Fink (Ed.), Stress: Concepts, Cognition, Emotion and Behavior. Handbook of Stress (Vol. 1, pp. 101-108). Sydney: Elsevier, https://doi.org/10.1016/B978-0-12800951-2.00012-1.

Yan, S., Xu, R., Stratton, T. D., Kavcic, V., Luo, D., Hou, F., et al. (2021). Sex differences and psychological stress: Responses to the COVID-19 pandemic in China. BMC Public Health, 21(1), 1-8. https://doi. org/10.1186/S12889-020-10085-W

Publisher's Note Springer Nature remains neutral with regard to jurisdictional claims in published maps and institutional affiliations. 